\title{
Parasites in marine systems
}

\author{
EDITED BY R. POULIN \\ CO-ORDINATING EDITOR L. H. CHAPPELL
}

\section{Preface}

The sea is the last frontier for biologists. The oceans are not only a major source of food for much of humanity, they are also the repository of most of the Earth's biodiversity. We know relatively little about the interactions among their inhabitants, however, and this is especially true with respect to parasitic organisms. This supplement consists of 12 review articles, written by international experts, each summarising and synthesising the available information on key aspects of the biology of marine parasites.

The topics included cover the evolution and ecology of marine host-parasite associations, as well as applied aspects of marine parasitology with commercial repercussions. Hoberg \& Klassen and Cribb et al. begin by looking at the co-evolution and biogeography of host-parasite associations in different marine systems. An evolutionary perspective is necessary to understand how assemblages of different parasite species have come to share the same hosts, but it is ecological processes that determine the structure of these assemblages. The next two papers examine the species interactions and structure of parasite assemblages in the two beststudied marine host-parasite systems: larval trematodes in gastropods (Curtis), and ectoparasites on fish (Morand et al.). Fish ectoparasites are unusual in that they are subjected to predation by cleaner organisms, and thus are at the basis of one of the best-known marine symbioses; Grutter takes a look at these cleaning symbioses from the parasites' perspective.

On a larger scale, parasites are fundamental components of marine food webs and ecosystems. Marcogliese discusses the transmission patterns of parasites in marine food webs. His paper is followed by two reviews of the impact of parasitism on marine ecosystems: in intertidal habitats (Mouritsen \&
Poulin) and in the Baltic Sea, where anthropogenic environmental changes are known to affect parasites (Zander \& Reimer). The importance of parasites in ecosystems becomes clear when they are introduced to new areas; Torchin et al. examine the impact of introduced parasites on native ecosystems, and the role played by parasites in determining the invasion success of exotic, non-parasitic species. The ubiquitous nature of parasites in marine systems means that they will have commercial importance in fisheries and aquaculture. On the positive side, they can be used as biological tags for stock discrimination, as highlighted by MacKenzie. On the negative side, many parasites are serious pathogens of commercially important host species; the supplement ends with two case studies of parasites with major impacts on their hosts, salmon lice (Tully \& Nolan) and sealworm (McClelland).

I thank the contributors for their efforts in putting together this collection of up-to-date reviews. I must also acknowledge the 23 referees (the 5 who are themselves contributors and the 18 others who are not) who put in some time to improve the reviews, and Les Chappell, the co-ordinating editor, who very efficiently oversaw the whole project. As a whole, the reviews in this supplement present an easy-to-read, comprehensive account of recent advances in the study of marine parasites. I hope that they will stimulate students and professional scientists interested in parasitology, fisheries, marine ecology, community and ecosystem biology, and evolutionary biology, to pursue the many open questions still left to be tackled.

ROBERT POULIN Fanuary 2002 